\title{
EL MONÓLOGO DRAMÁTICO EN LA POESÍA DE JOSÉ EMILIO PACHECO
}

\author{
POR \\ Maria Rosa Olivera-Williams \\ University of Notre Dame
}

Desde hace varias décadas la poesía del escritor mexicano José Emilio Pacheco ocupa un lugar de merecida importancia en la historia de la literatura latinoamericana. La agudeza crítica de Ángel Rama señalaba ya en 1978 que Pacheco "no es el individuo roto y aislado que tanto propone la poesía moderna", por el contrario, "él aparece como el miembro de una especie, como tal dotada de una oscura memoria ancestral que lo integra a una ambición conjunta, vasta y extendida como la especie toda". ${ }^{1}$ Pacheco lleva adelante la difícil tarea de mantener vivo un género que a través de su larga existencia ha sufrido no pocas veces la falta de entendimiento del receptor, su indiferencia, o su admiración por todas las razones equivocadas: se admira la figura pública de quien habla en conferencias o es entrevistado en la televisión, pero no se lee lo que escribe. ${ }^{2}$ Pacheco como miembro de una "especie" tan antigua como la humanidad misma re-crea constantemente las voces de los poetas que lo precedieron y unido a ellas observa, reflexiona, escribe poesía sobre nuestro tiempo.

En la poesía de Pacheco se oyen ecos de la Biblia, de los clásicos, de escritores contemporáneos, de música popular, de anuncios comerciales y todas estas alusiones culturales son apropiadas por una voz poética que se acerca a los registros del habla conversacional. La facilidad con que Pacheco hace suyo el acervo cultural, el tono coloquial de sus poemas han animado a muchos críticos a catalogar su poesía de "conversacional", especialmente después de la publicación de No me preguntes cómo pasa el tiempo, 1969. Los críticos que siguen refiriéndose a la poesía de Pacheco como "conversacional" no advierten que si bien algunos poemas entran en esta categoría no toda su poesía es conversacional. Esta situación nos recuerda a la del poeta americano Robert Frost. En 1953 Randall Jarrell se quejaba de lo mal que se había leído a Frost e indicaba que para el lector común uno de los logros de Frost era que sus poemas se leyeran como prosa (Jarrell 29). Con referencia a la producción poética latinoamericana el término "poesía conversacional" se aplica a poemas que comienzan a publicarse en los 50 y cuyas características son lo cotidiano, lo claro, lo sentimental y sobre todo lo social. En otro trabajo ${ }^{3}$ aludíamos a la

\footnotetext{
' Ver de Ángel Rama “Reflejos en un ojo interrogante" en "Culturales”, El Nacional (Caracas, 1978). ${ }^{2}$ Ver de José Emilio Pacheco "Una defensa del anonimato" en Los trabajos del mar (México: Era, 1983) 72-75.

${ }^{3}$ Ver mi artículo "Ciudad de la memoria de José Emilio Pacheco: un nuevo capítulo para un poemario único". Revista Hispánica Moderna, XLV/2 (December 1992) 242-251. Reimpreso en Literatura Mexicana (México: Universidad Autónoma de México, II/2, 1991) 439-453.
} 
amplitud del concepto, ya que esta lírica abarca temas desarrollados por otras tendencias poéticas. Parecería entonces que lo que diferencia a esta poesía de otras es el tono coloquial, el uso de un lenguaje que incorpora frases y figuras verbales usadas en la conversación o en la prosa. No podemos menos que recordar que ya en 1802 William Wordsworth proponía para sus poemas un lenguaje que se acercara al lenguaje real de los hombres sencillos (ver el prólogo a Lyrical Ballads). Wordsworth buscaba romper con lo que se entendía en su tiempo por dicción poética. Anhelaba encontrar un lenguaje poético carente de artificios como el medio lingüístico para aprehender la verdad. Para Wordsworth: "the language of a large portion of every good poem, even of the most elevated character, must necessarily, except with reference to the meter, in no respect differ from that of good prose". Pero el lenguaje poético no puede ser leído igual al lenguaje de la prosa aunque el lenguaje poético haya ido ampliando gradualmente sus registros desde el romanticismo. E1 lenguaje prosaico de cierta poesía, por el simple hecho de estar incorporado en el verso, se carga de nuevo significado. Los espacios en blanco que equivalen a los silencios de la música y separan los versos imponen un significado diferente a las palabras que en prosa formarían una frase. Si bien un ejemplo clásico sería citar "This is just to say ..." de William Carlos Williams, qué mejor poema que el de Pacheco "Una defensa del anonimato" (Carta a George B. Moore para negarle una entrevista)" para iluminar lo dicho:

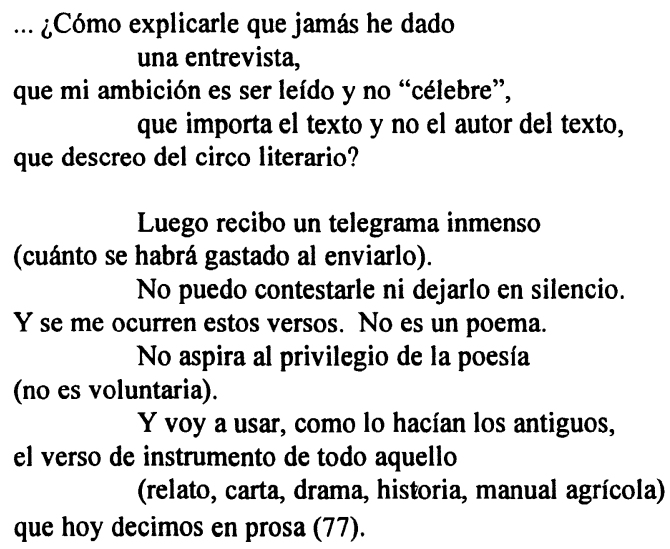

Samuel Taylor Coleridge, quien colaboró con Wordsworth en Lyrical Ballads, objeta la asimilación del lenguaje poético con el prosaico que Wordsworth propone en su teoría. E1 lenguaje real de los hombres sencillos de Wordsworth corresponde a unos campesinos abstractos, removidos del mundo de fragmentación y extrañamiento que como observa $\mathrm{M}$. $\mathrm{H}$. Abrams caracteriza al periodo romántico. Con un lenguaje universal y homogéneo, Wordsworth propone una solución idealista a la alienación que sufre el individuo. Como Coleridge indica, el lenguaje de Wordsworth es asimismo un artificio poético. Coleridge, por su parte, quien subtitula uno de los poemas de Lyrical Ballads, "The Nightingale", "A Conversational Poem", crea un nuevo tipo de poesía que si bien emplea un lenguaje sencillo, 
según la tendencia propuesta por Wordsworth, su novedad radica en el personaje dramático. Lo conversacional de esta poesía se halla en el artificio de crear una conversación entre el personaje dramático y los miembros de la familia del poeta, lo que le permite a Coleridge llegar a algunas especulaciones metafísicas. El desarrollo de la persona poética es a mi juicio el elemento de mayor interés para entender la evolución de la poesía contemporánea. Si en Coleridge el personaje dramático es una creación subjetiva que le permite al poeta hablar consigo mismo (el destinatario, a quien se dirige el personaje dramático, es un artificio, no le responde) y de esta manera proyectar en sus poemas su forma de ser y de sentir, la evolución del monólogo dramático abre nuevas avenidas para la poesía posterior.

En la poesía de Robert Browning, maestro del "monólogo dramático", la persona dramática le permite al poeta distanciarse de su poema. No es el poeta quien habla por medio de la persona dramática. En Poetry and the Age (1953), Randall Jarrell indica: "the dramatic monologue, which once had depended for its effect upon being a departure from the norm of poetry, now became in one form or another the norm" (13). En 1969, Richard Howard dedicó sus monólogos a Browning: "to the great poet of otherness ... who said, as I should like to say, "I'll tell my state as though't were none of mine". El monólogo dramático de Browning le permite al lector, al hablante y al poeta distanciarse y de esta manera buscar el significado del poema a través de las palabras del personaje dramático (ver The Ring and the Book).

Loy D. Martin observa con agudeza que Browning crea con el monólogo dramático un discurso abierto que sólo invoca técnicas tradicionales de simetría y conclusión irónicamente para negar sus efectos tradicionales. Para Martin: "The monologue is always, among other things, a deictic gesture toward the fading and uncertain vistas of a linear dimension of time and speech" (25). El tiempo pierde su naturaleza cronológica en el monólogo. El pasado no tiene una realidad palpable. No puede ser representado poéticamente. Hay una continuidad entre el momento del poema y el tiempo (pasado-presente-futuro) que va más allá del discurso del texto. Asimismo el lenguaje de la conversación y el lenguaje poético se funden. Ya no existe la separación arbitraria entre el artificio del lenguaje poético y el lenguaje natural de los hombres. Esto no implica que el lenguaje poético se haya transformado en un lenguaje prosaico, sino que las convenciones formales del verso se enlazan con la dicción coloquial y con los giros lingüísticos y ritmos del habla común. Otros tiempos, otros lenguajes, otras culturas se funden en el monólogo dramático. Si en la poesía victoriana de Browning y sus contemporáneos, el monólogo dramático, gracias a personajes que articulan culturas, lugares y tiempos diferentes, cuestiona la separación del presente de la Inglaterra del siglo XIX de su pasado político y cultural así como también el extrañamiento entre una Inglaterra que se desarrollaba rápidamente y lugares distantes y exóticos, el monólogo dramático en la poesía contemporánea pone a prueba las posibilidades de la comunicación como una fuerza de cohesión social. E1 personaje dramático como una entidad que se constituye en el lenguaje $e^{4}$ presenta un centro hipotético de comunicación,

\footnotetext{
${ }^{4}$ Para Jacques Lacan el sujeto está continuamente siendo creado en lo que él llama "el discurso del otro": "All that is language is lent from this otherness and this is why the subject is always a fading thing that runs under the chain of signifiers .... The sign is something that represents something for somebody, but the signifier is something that represents a subject for another signifier. The
} 
pero ese mismo lenguaje que lo crea lo funde con otros individuos, otros tiempos, otros lugares, otras razas. Con palabras de Martin:

the speaker of a dramatic monologue is always a fragmentary splitting off from the creative force of his or her discourse [...] the individual speaker can never wholly represent the unitary "author" of the poem [...] The struggle between the subject as homogeneous "true person' and as heterogenous end 'disappearing' moment of speech and signification gives the dramatic monologue its form, a form that can never resolve the contradiction at its center (30-31).

En nuestro tiempo, que a pesar de las innumerables controversias al respecto, podemos llamar "posmoderno", en el cual vivimos la crisis de una modernidad que según Habermas ha sido incompleta, en la que tratamos de superar falsas antinomias de la modernidad, se reivindica lo fragmentario, lo ecléctico y se descubre y valora el sujeto social heterogéneo que la modernidad se empeñaba en ignorar, el monólogo dramático se constituye en un excelente vehículo del pensamiento de nuestro tiempo, del pensamiento posmoderno. ${ }^{5}$

E1 lenguaje de la poesía de José Emilio Pacheco se crea por medio de la fragmentación, re-creación y redistribución de otros textos literarios y sociales, por ello, el hablante constituido por este lenguaje es necesariamente heterogéneo. Los textos incorporados en sus poemas se despojan de su consistencia ideológica y el poema se convierte en un proceso productivo de defamiliarización del sujeto. Es conveniente recordar que Julia Kristeva encuentra que el lenguaje poético puede mantener y defamiliarizar, apoderándose de un término que los formalistas rusos aplican a la representación de un objeto común como si fuera extraño en la narrativa, las limitaciones ideológicas de su lenguaje. Así la poesía puede defamiliarizar la realidad objetiva o social, pero principalmente puede defamiliarizar al propio sujeto. Partamos con el poema anteriormente citado, "Una defensa del anonimato". Aquí el hablante se indentifica con el autor del poema; es José Emilio Pacheco que se dirige a un receptor determinado, George B. Moore:

No sé por qué escribimos, querido George.

$\mathrm{Y}$ a veces me pregunto por qué más tarde publicamos lo escrito.

Es decir, lanzamos una botella al mar, que está repleto de basura y botellas con mensajes. Nunca sabremos

a quién ni adónde la arrojarán las mareas (72).

consequence is that the subject disappears ... while under the second signifier appears what is called meaning or signification; and then in sequence the other signifiers appear and other significations". Esta respuesta de Jacques Lacan a Charles Morazé aparece en The Structuralist Controversy, The Languages of Criticism, and the Sciences of Man. eds. Richard Macksey y Eugenio Donato (Baltimore: Johns Hopkins University Press, 1972) 194.

${ }^{5}$ Ver los ensayos que aparecen en el volumen dedicado a "Modernidad y Posmodernidad en América Latina" en Nuevo Texto Crítico 6. Año III, (Segundo semestre de 1990). 
Sin embargo, desde el primer verso, el "yo" del hablante se confunde con el "nosotros" de todos los que escriben. No existe aquí el deseo de una unidad subjetiva, aunque no lograda, que está presente en "One Word More" de Browning:

Love, you saw me gather men and women,

Live or dead or fashioned by my fancy,

Enter each and all, and use their service,

Speak from every mouth, - the speech, a poem,

Hardly shall I tell my joys and sorrows,

Hopes and fears, beliefs and disbelieving:

Let me speak this once in my true person,

(Men and Women, XIV, 363)

La verdadera persona del hablante en "Una defensa del anonimato" es la que no interesa, la que niega la entrevista a George Moore. El "yo" múltiple que se está creando en el poema es el que "lanza" una "botella con mensajes al mar". La acción de lanzar la botella, de publicar el poema, es una invitación a ser leído, ya que por medio de la lectura se hace posible la comunicación y el hablante dramático se multiplica y se pierde en las lecturas del poema. E1 discurso privado entre la persona dramática y George Moore desaparece y el poema sólo existe como una invitación abierta a ser re-creado:

\author{
Escribo y eso es todo. Escribo: doy la mitad del \\ poema. \\ Poesía no es signos negros en la página blanca. \\ Llamo poesía a ese lugar del encuentro \\ con la experiencia ajena. E1 lector, la lectora \\ harán, o no, el poema que tan sólo he esbozado (74).
}

Si Browning descubre cuando se introduce momentáneamente en la ideología de la lírica romántica que su "verdadera persona", la que le corresponde a él y a su amada, Elizabeth Barrett, está de todas formas en sus poemas, en las voces de los hombres y mujeres por quienes habla ("Though the fruit of speech be just this sentence:/Pray you, look on these my men and women,/ Take and keep my fifty poems finished;/ Where my heart lies, let my brain lie also!/Poor the speech; be how I speak, for all things"'(363), en el poema de Pacheco, el hablante es uno más de los hombres y mujeres que en sus lecturas re-hacen el poema. Browning se encuentra o mejor dicho desea encontrarse a través de sus creaciones dramáticas, Pacheco, por otra parte, se pierde en las suyas. Pero es precisamente en la defamiliarización del sujeto poético, en el momento que se vuelve heterogéneo y desaparece, que radica la fuerza de su poesía:

El poeta dejó de ser la voz de su tribu, aquel que habla por quienes no hablan.

Se ha vuelto nada más que otro entertainer.

Sus borracheras, sus fornicaciones, su historia clínica, 
sus alianzas o pleitos con los demás payasos del circo, o el trapecista o el domador de elefantes, tienen asegurado el amplio público a quien ya no hace falta leer poemas.

Si le gustaron mis versos qué más da que sean míos/de otros/de nadie.

En realidad los poemas que leyó son de usted: Usted, su autor, que los inventa al leerlos (74-75).

Pacheco, como observó Rama, sigue siendo "la voz de la tribu", pero no "habla por quienes no hablan", lo que lo colocaría en la tradición poética de un Whitman o un Neruda, sino que a través del hablante se transforma en una voz más dentro de las voces de la tribu. E1 que no habla comienza a hacerlo en el momento de leer el poema, en el momento de asumir la voz del hablante dramático. Así como esta carta en verso se transforma en un poema, ya que la poesía "no es voluntaria", el receptor del mismo, George Moory, se ha perdido en los múltiples lectores del poema. E1 hablante y el receptor desaparecen, se transforman, se multiplican actuando el deseo de ser los creadores anónimos de unos pocos buenos poemas. E1 monólogo dramático invita a que el lector continúe y colabore en la creación del poema con su propia participación imaginativa. E1 poeta se transforma en un lenguaje que debe ser completado por un acto de repuesta. Browning en su introducción a Paracelsus ya sentía la necesidad de un lenguaje poético que necesitara de la colaboración del lector:

It is certain, [...] that a work like mine depends more immediately on the intelligence and sympathy of the reader for its success: indeed were my scenes stars, it must be his cooperating fancy which, supplying all chasms, should connect the scattered lights into one constellation - a Lyre or a Crown (Brownidg, 12).

Si bien "Una defensa del anonimato" ilustra la desaparición del "yo" personal y su recreación y transformación en las diversas lecturas del poema, no es el mejor ejemplo para apreciar cómo Pacheco funda el lenguaje poético con el común, y los ritmos familiares con las convenciones de otros tiempos así como también las voces de otros poetas con la suya.

E1 monólogo dramático requiere un hablante, la creación de un personaje que se dirige a un receptor. En Princeton Encyclopedia of Poetry and Poetics se dice del monólogo: "Despite its limitation to a single speaker, the monologue naturally assumes a dramatic character. For vocalization itself craves an object —one or many persons to constitute an audience. Thus the audience as well as the speaker becomes a part of the total area of imagination. [...] The monologue requires not only a single speaker but an advanced degree of impersonation" (529). E1 personaje dramático que se va constituyendo por medio del discurso asimismo va creando a su objeto -el destinatario. E1 monólogo dramático, a pesar de ser la enunciación de un hablante, implica el deseo de un diálogo, el deseo de comunicación. Esta comunicación parece ser cada vez mas frágil y vulnerable en nuestro tiempo. Sin embargo, como el monólogo dramático presenta las estructuras de reciprocidad e intercambio (el monólogo que quiere ser diálogo, o el diálogo que se ha transformado en 
monólogo) aunque el interlocutor no responda en el poema, el receptor (lector u oyente) debe actuar el poema retomando la voz del personaje dramático y el silencio del interlocutor. En el poderoso poema "Prosa de la calavera", ${ }^{6}$ Pacheco toma el versículo bíblico para crear un personaje dramático singular y plural, la calavera (la máscara de la muerte) que se dirige a un receptor singular y plural (tú, nosotros, vosotros, ustedes, los otros):

\section{Como Ulises me llamo Nadie. Como el demonio de} los Evangelios mi nombre es Legión.

Soy tú porque eres yo. $\mathrm{O}$ serás porque fui.

Tú y yo. Nosotros dos. Vosotros, los otros. Los innumerables ustedes que se resuelven en mí (25).

La calavera que se dirige a los seres humanos pare mostrarles su naturaleza transitoria y hacerles tomar conciencia de ella es simultáneamente hablante y receptor: "Soy tú porque eres yo". El lector que debe ser consciente de lo vulnerable y perecedero de todas sus obras así como también de lo perecedero de su ser debe asumir la voz de la calavera y la de su interlocutor ya que la calavera es el reflejo de su interlocutor. Aquí como en el poema de E. A. Robinson, "Rembrandt to Rembrandt", el personaje dramático no habla consigo mismo. Si en "Rembrandt to Rembrandt" una fase del alma del pintor aparece hablando con otra en su espejo, esa otra podría materializarse en su esposa muerta; en el poema de Pacheco la calavera se dirige a los vivos. En ambos poemas los hablantes y sus interlocutores personifican distintas etapas y por lo tanto son distintas personas. El monólogo dramático de Pacheco enfrenta al lector con su mortalidad por medio del discurso de la calavera. El poema se transforma en el espejo en el cual el lector debe contemplarse.

Una de las convenciones del monólogo dramático señalada por T. S. Eliot es el objeto correlativo. Cuando el personaje dramático de Pacheco se dirige a Efraín Huerta, Jorge Guillén, César Vallejo, Walter Benjamin, entre otros, o retoma las voces de Gustavo Adolfo Bécquer, Rainer Maria Rilke, Juan Ramón Jiménez, Jonás, Juan Rulfo, Dino Buzzati, Zbigniew Herbert, es porque en todos ellos hay puntos de encuentro con Pacheco. E1 poetacronista que observa con conciencia y por lo tanto con dolor los derrumbamientos de nuestro tiempo ("Campo, campo de sangre/ el mundo entero". "El cuchillo", en Ciudad de la memoria (52), que re-crea con palabras, que también dejarán de tener sentido, las obras de los seres humanos destruidas por ellos mismos, al unirse al esfuerzo de aquellos que lo precedieron muestra paradójicamente el poder de permanencia de la poesía.

Eliot se quejaba ya en "The Love Song of J. Alfred Prufrock" (1917), luego en "The Waste Land" (1922) y finalmente en su gran poema The Four Quartets (1943) de la imposibilidad de aprehender el presente en el lenguaje:

So here I am, in the middle of the way, having had twenty yearsTwenty years largely wasted, the years of l'entre deux guerresTrying to learn to use words, and every attempt

${ }^{6}$ Este poema se publicó por primera vez en 1981 para acompañar una serie de grabados de Miguel Cervantes y luego pasó a ser una sesión de Los trabajos del mar (México: Era, 1983). 
Is a wholly new start, and a different kind of failure Because one has only learnt to get the better of words For the thing one no longer has to say, ... ("East Coker", V) ${ }^{7}$

Para Pacheco también es difícil aprehender el presente ("Porque al fin y al cabo/creó este presente el porvenir que choca/ con el pasado" ("Los vigesémicos" en Ciudad de la memoria, 27), ya que no sólo es el choque de dos tiempos que no son: el pasado y el futuro, sino que y con sus palabras junto a las de Bécquer y Rilque: "Para nosotros, los más efímeros de todos,/ una vez cada cosa. Nada más: nunca más./ Y nosotros también nunca de nuevo" ("Bécquer y Rilque se encuentran en Sevilla" en Ciudad de la memoria, 44). Así los intentos de rescatar algunos instantes de ese presente por medio de la poesía parecerían reducirse a un "Archivo sin cuento/ de words, words, words,/ el blablablá interminable/ que sólo es aire para que el aire lo escuche" ("Hamletiana", Ciudad de la memoria, 17). Sin embargo, el esfuerzo no es vano. En los espacios en blanco que separan los versos, en los silencios de la música del poema algo queda que hace posible que los lectores retomen y re-creen el poema. El personaje dramático de "Elegía de San Juan de Letrán pare Efraín Huerta" (Los trabajos del mar) dice:

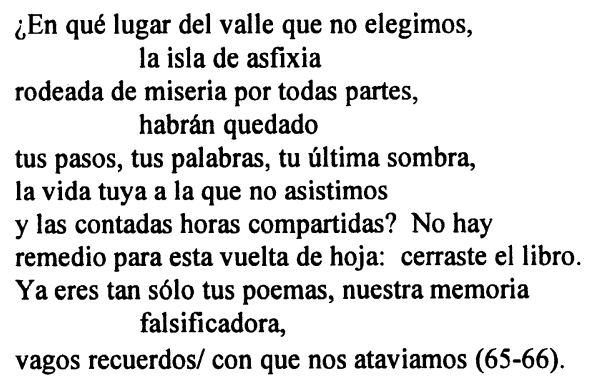

A la muerte de Efraín Huerta lo que quedan son sus poemas y "nuestra memoria falsificadora", la que nos permite re-actuar sus poemas, darles nueva vida, hacerlos nuestros como Pacheco está haciendo suyos algunos versos de Huerta. Retomando un género, el monólogo dramático, cuyos orígenes pueden remontarse a las Heroidas de Ovidio, y que en México alcanzó nuevos logros en poemas como "Lamentación de Dido" (1957), "Monólogo de la extranjera", (Al pie de la letra, 1959), "Testamento de Hécuba" (Materia memorable, 1969), "Kinsey Report"(1972)y “Autorretrato"(1972), de Rosario Castellanos, Pacheco encuentra un excelente vehículo para dialogar con los lectores y mostrarles que la vida es terrible, absurda y sobre todo, gloriosa. Dije dialogar, pero debería decir para intentar dialogar con los lectores ya que utilizando su propia traducción de Cuatrocuartetos de T. S. Eliot: "Para nosotros sólo existe el intento./Lo demás no es asunto nuestro" (26).

\footnotetext{
${ }^{7}$ Es interesante seffalar que en 1989 Pacheco publicó la traducción al español del poema de T. S. Eliot. Cuatro cuartetos (Traducción de José Emilio Pacheco) (México: Fondo de Cultura Económica, 1989).
} 
El monólogo dramático a través de la creación de hablantes diferentes le permite al lector y al mismo Pacheco descubrirse por medio de la lectura/escritura. Daryl Hine en el prefacio a su traducción en verso de las Heroidas de Ovidio dice que a través de las voces de estas grandes mujeres de la Edad Heroica descubre la inigualable voz del poeta romano:

[...] the poet-ventriloquist's lips can be seen, stylistically, to move, so that the challenge to the mimic translator is to catch behind or within the voice of each victim-heroine the inimitable Ovidian tone. Bantering, ironical, elaborate, and often epigramatic, when these qualities ill become dramatic naturalism, the words of Oenone or Phaedra, Briseis or Hermione, are always audibly those of our wordly, ingenious Roman author (IX).

Si bien en la poesía de Pacheco no notamos al poeta ventrílocuo y no lo notábamos ya en la poesía de Browning, el ser que se forma en la lengua poética de sus monólogos dramáticos y con la ayuda imaginativa de los lectores es Pacheco. Si la voz de Ovidio es inconfundible, aunque las que hablan son sus "Heroines", la de Pacheco también lo es y no porque su tono permee las voces de sus hablantes. La voz de Pacheco surge de la multiplicidad de sus personajes dramáticos y se va constituyendo a lo largo de sus poemarios. Si Rosario Castellanos se sorprendía de encontrar datos autobiográficos en su gran monólogo dramático "Lamentación de Dido", así como en el "Monólogo de la extranjera", en los monólogos de Pacheco no encontramos mayores referencias autobiográficas. Sin embargo, cuando sentimos las voces de sus personajes dramáticos, que parecen no sólo intentar comunicarse con el interlocutor o interlocutores creado o creados en el poema sino también entre los personajes dramáticos de otros poemas, la voz múltiple que escuchamos y actuamos en nuestras lecturas es la de Pacheco.

\section{OBRAS CITADAS}

Abrams, M.H. Natural Supernaturalism. New York: Norton, 1973.

Browning, Robert. The Complete Poetic and Dramatic Works of Robert Browning. Boston \& New York: Houghton Mifflin Company, 1895.

The Ring and The Book. En The Complete Poetic and Dramatic Works of Robert Browning.

Castellanos, Rosario. Al pie de la letra. Xalapa: Universidad Veracruzana, 1959. Materia memorable. México: Universidad Nacional Autónoma de México, 1969. Poesía no eres tú: Obra poética. 1948-1971. 1 $1^{\mathrm{a}}$ ed. México: Fondo de Cultura Económica, 1972; $2^{\mathrm{a}}$ edición, 1975.

Coleridge, Samuel Taylor. The Complete Poetical Works of Samuel Coleridge. 2 vols. Ernest Hartley Coleridge, editor. Oxford: Clarendon Press, 1912.

Eliot, T.S. Four Quartets. New York: Harcourt Brace Jovanovich, 1971. Cuatro Cuartetos. (Traducción de José Emilio Pacheco). México: Fondo de Cultura Económica, 1989.

Hine, Daryl. A Verse Translation of the Heroides. Ovid's Heroines. New Haven-London: Yale University Press, 1991.

Jarrell, Randall. Poetry and the Age. New York: Alfred A. Knopf, 1953. 
Kristeva, Julia. Desire in Language. Leon S. Roudiez, editor. New York: Columbia University Press, 1980.

Lacan, Jacques. The Structuralist Controversy. The Languages of Criticism and the Sciences of Man. Richard Macksey y Eugenio Donato, editores. Baltimore: Johns Hopkins University Press, 1972.

Martin, Loy D. Browning's Dramatic Monologue and the Post-Romantic Subject. Baltimore \& London: The Johns Hopkins University Press, 1985.

Olivera-Williams, María Rosa. "Ciudad de la memoria de José Emilio Pacheco: un nuevo capítulo hacia la creación de un poemario único". Revista Hispánica Moderna, XLV/ 2 (December 1992). Reprinted in Literatura Mexicana: Universidad Autónoma de México, II/2, (1991) 439-453.

Pacheco, José Emilio. No me preguntes cómo pasa el tiempo. México: Joaquín Mortiz, 1969.

Los trabajos del mar. México, Monterrey: Universidad Autónoma de León, 1982. $2^{\mathrm{a}}$ ed. ampliada, México: Era, 1983.

Ciudad de la memoria. México: Era, 1989.

Preminger, Alex, comp. Princeton Encyclopedia of Poetry and Poetics. Princeton: Princeton University Press, 1974.

Rama, Ángel. "Reflejos en un ojo interrogante". "Culturales". El Nacional. Caracas, Venezuela, 1978.

Robinson, Edwin Arlington. Collected Poems of Edwin Arlington Robinson. New York: The Mac Millan Co., 1974.

Ruffinelli, Jorge. ed. "Modernidad y Posmodernidad en América Latina". Nuevo Texto Crítico 6. Año III, (Segundo semestre de 1990).

Wordsworth, William \& Coleridge, Samuel Taylor. Lyrical Ballads. ed. R. L. Brett and A.R. Jones. London \& New York: Methuen, [1798] 1986. 